\title{
MEMBANGUN SEMANGAT PERSATUAN DAN KESATUAN MELALUI GERAKAN PRAMUKA
}

\section{LEDISTA DEANUR}

\section{IIK STRADA INDONESIA}

\section{ledistadeanur@gmail.com}

\begin{abstract}
ABSTRAK
Persatuan dan kesatuan bangsa dalam negara kesatuan yang adil dan makmur, materiil dan spiritual serta beradab merupakan adicita Bangsa Indonesia yang mulai bangkit dan siaga sejak berdirinya Boedi Oetomo pada tanggal 20 Mei 1908. Adicita itu pulalah yang merupakan dorongan para pemuda Indonesia melakukan Sumpah Pemuda pada tanggal 28 Oktober 1928. Dalam upaya Menggalang persatuan untuk merebut kemerdekaan dan dengan jiwa dan semangat Sumpah Pemuda, rakyat Indonesia berjuang untuk kemerdekaaan nusa dan bangsa Indonesia yang diproklamasikan pada tanggal 17 Agustus 1945. Selayaknya seluruh warganya mempunyai jiwa persatuan dan kesatuan yang tinggi, akan tetapi rasa persatuan dan kesatuan bangsa Indonesia saat ini dirasa semakin berkurang, mengalami krisis persatuan dan kesatuan. Banyak orang yang lebih mementingkan kepentingan pribadi daripada kepentingan umum, sehingga hilangnya persatuan dan kesatuan ini dapat menyebabkan timbulnya disintegrasi bangsa. hal ini terbukti dengan adanya perpecahan suku, perselisihan atau permusuhan dalam agama maupun antar agama. Gerakan pramuka merupakan organisasi pendidikan nonformal yang menyelenggarakan pendidikan kepanduan yang dilaksanakan di Indonesia. Kata "Pramuka" merupakan singkatan dari Praja Muda Karana, yang memiliki arti rakyat muda yang suka berkarya. Melalui gerakan pramuka tersebut bertujuan mendidik anak-anak dan pemuda Indonesia dengan prinsip-prinsip dasar dan Metode Kepramukaan yang pelaksanaannya disesuaikan dengan keadaan, kepentingan dan perkembangan untuk membangun kesatuan dan kesatuan. Berdasarkan latar belakang permasalahan di atas maka dapat dirumuskan suatu permasalahan sebagai berikut yaitu Bagaimanakah pelaksanaan Gerakan pramuka dalam membangun jiwa persatuan dan kesatuan serta Bagaimanakah peranan kegiatan gerakan pramuka dalam membangun jiwa persatuan dan kesatuan?.
\end{abstract}




\section{LATAR BELAKANG}

Persatuan dan kesatuan bangsa dalam negara kesatuan yang adil dan makmur, materiil dan spiritual serta beradab merupakan adicita Bangsa Indonesia yang mulai bangkit dan siaga sejak berdirinya Boedi Oetomo pada tanggal 20 Mei 1908. Adicita itu pulalah yang merupakan dorongan para pemuda Indonesia melakukan Sumpah Pemuda pada tanggal 28 Oktober 1928. Dalam upaya Menggalang persatuan untuk merebut kemerdekaan dan dengan jiwa dan semangat Sumpah Pemuda, rakyat Indonesia berjuang untuk kemerdekaaan nusa dan bangsa Indonesia yang diproklamasikan pada tanggal 17 Agustus 1945. Kemerdekaan ini merupakan berkat dan rahmat Tuhan Yang Maha Esa. Bangsa Indonesia dikenal sebagai bangsa majemuk, ditandai banyaknya etnis, suku, agama, budaya, kebiasaan, di dalamnya. Di sisi lain masyarakat Indonesia dikenal sebagai masyarakat multikultural, masyarakat yang anggotanya memiliki latar belakang budaya beragam.

Kemajemukan dan multikulturalitas mengisyaratkan adanya perbedaan. Hendaknya perbedaan-perbedaan justru dijadikan perbendaraan dan sumber inspirasi yang tidak habis-habisnya untuk digali dan dikembangkan. Bhinneka Tunggal Ika berarti pengakuan terhadap kemacaman-ragaman yang ada dan sekaligus memperkembangkan mereka demi kekayaan bersama, sehingga persatuan bukan hanya persatuan yang kosong tetapi justru harus merupakn perpaduan yang semakin mapat dan padat dengan nilai-nilai yang bermacam ragam dan sekaligus membentuk kesatuan yang indah, harmonis dan damai. Sejak awal berdirinya Negara Kesatuan Republik Indonesia, para pendiri negara menyadari bahwa keberadaban masyarakat yang majemuk merupakan kekayaan bangsa Indonesia yang harus diakui, diterima, dan dihormati yang kemudian diwujudkan dalam semboyan Bhineka Tunggal Ika. Namun disadari bahwa ketidak mampuan untuk mengelola kemajemukan dan ketidaksiapan sebagai masyarakt untuk menerima kemajemukan tersebut serta pengaruh berkelanjutan politik kolonial dievide et imperate dan telah mengakibatkan terjadinya berbagai gejolak yang membahayakan persatuan dan kesatuan bangsa. Indonesia yang memiliki beragam kultur dan budaya, selayaknya seluruh warganya mempunyai jiwa persatuan dan kesatuan yang tinggi, akan tetapi rasa persatuan dan kesatuan bangsa Indonesia saat ini dirasa semakin berkurang, mengalami krisis persatuan dan kesatuan. Banyak orang yang lebih mementingkan kepentingan pribadi daripada kepentingan umum, sehingga hilangnya persatuan dan kesatuan ini dapat menyebabkan timbulnya disintegrasi bangsa. hal ini terbukti dengan adanya perpecahan suku, perselisihan atau permusuhan dalam agama maupun antar agama.

Gerakan pramuka merupakan organisasi pendidikan nonformal yang menyelenggarakan pendidikan kepanduan yang dilaksanakan di Indonesia. Kata "Pramuka" merupakan singkatan dari Praja Muda Karana, yang memiliki arti rakyat muda yang suka berkarya. Melalui gerakan pramuka tersebut bertujuan mendidik anak-anak dan pemuda Indonesia dengan prinsip-prinsip dasar dan Metode Kepramukaan yang pelaksanaannya disesuaikan dengan keadaan, kepentingan dan perkembangan bangsa dan masyarakat Indonesia. Dalam Anggaran Dasar Gerakan Pramuka hasil Munaslab Tahun 
2012 Bab II Pasal 3 Tujuan Gerakan Pramuka adalah untuk membentuk setiap pramuka agar memiliki kepribadian yang beriman, bertaqwa, berakhlak mulia, berjiwa patriot, taat hukum, disiplin, menjunjung tinggi nilai-nilai luhur bangsa, dan memiliki kecakapan hidup sebagai kader dalam menjaga negara kesatuan Republik Indonesia, mengamalkan pancasila serta melestarikan lingkungan hidup, sehingga menjadi angota masyarakat yang baik dan berguna, yang sanggup dan mampu menyelanggarakan pembangunan bangsa dan negara. Peranan kegiatan pramuka perlu ditanamkan kepada generasi muda sebagai ujung tombak penerus bangsa, dengan memberikan pendidikan baik melalui pendidikan formal maupun non-formal. Hal ini penting guna pertumbuhan dan perkembangan anak, sebagai wadah pembentukan dan pembinaan generasi muda yang mandiri, berkualitas, serta untuk menumbuhkan generasi yang beretos kerja tinggi. Maka dari itu gerakan Praja Muda Karana sangat perlu digiatkan dan dikembangkan dilingkungan sekolah untuk mendidik para pelajar sebagai generasi penerus bangsa agar memiliki rasa persatuan dan kesatuan, serta menjunjung tinggi rasa cinta tanah air dan bangsa. Berdasarkan latar belakang di atas maka dilakukan penelitian untuk mengetahui Peranan Kegiatan Pramuka dalam Membangun Jiwa Persatuan dan kesatuan.

\section{2. .KASUS/MASALAH}

Berdasarkan latar belakang permasalahan di atas maka dapat dirumuskan suatu permasalahan sebagai berikut yaitu Bagaimanakah pelaksanaan Gerakan pramuka dalam membangun jiwa persatuan dan kesatuan serta Bagaimanakah peranan kegiatan gerakan pramuka dalam membangun jiwa persatuan dan kesatuan.

\section{PEMBAHASAN}

\section{Gerakan Kegiatan Pramuka}

Gerakan Pramuka adalah proses pendidikan diluar lingkungan sekolah dan di luar lingkungan keluarga dalam bentuk kegiatan menarik, menyenangkan, sehat, teratur, terarah, praktis yang dilakukan di alam terbuka dengan prinsip dasar kepramukaan, yang sasaran akhirnya membentuk watak, akhlak dan budi pekerti luhur (Undang-undang No 2 Tahun 2010).

\section{Membagun Jiwa}

Pengertian Membangun Jiwa. Membangun artinya bangkit berdiri; naik (Tim Redaksi Kamus Besar Bahasa Indonesia (2005:103). Definisi lain yaitu membangun adalah bangkit berdiri, mendirikan, membina memperbaiki, membayar bangunan. Jiwa artinya roh manusia (yang ada di dl tubuh dan menyebabkan seseorang hidup); nyawa, seluruh kehidupan batin manusia (yg terjadi dari perasaan, pikiran, angan-angan), sesuatu atau orang yg utama dan menjadi sumber tenaga dan semangat, buah hati, orang, daya hidup orang atau makhluk hidup lainya. Definisi lain jiwa adalah kesempurnaan awal, karena dengannya spesies menjadi sempurna sehingga menjadi manusia yang nyata, artinya jiwa merupakan kesempurnaan awal bagi tubuh (Yunos:2012). Dengan demikian membangun 
jiwa adalah bangkit berdiri, membina kebaikan untuk menjadi manusia yang nyata dan sempurna

\section{Persatuan dan Kesatuan}

Persatuan adalah gabungan beberapa bagian yang sudah Bersatu. Persatuan berasal dari kata satu yang berarti utuh, tidak pecah belah, persatuan mengandung pengertian disatukannya berbagai macam corak yang 7 beraneka ragam menjadi satu kebulatan. Dengan perkataan lain, hal-hal yang beraneka ragam itu, setelah disatukan, menjadi sesuatu yang serasi, utuh dan tidak saling bertengkar antara satu dengan yang lain. (Kansil dan Kansil 2005:75).

\section{KESIMPULAN}

Sejak awal berdirinya Negara Kesatuan Republik Indonesia, para pendiri negara menyadari bahwa keberadaban masyarakat yang majemuk merupakan kekayaan bangsa Indonesia yang harus diakui, diterima, dan dihormati yang kemudian diwujudkan dalam semboyan Bhineka Tunggal Ika Selayaknya seluruh warganya mempunyai jiwa persatuan dan kesatuan yang tinggi, akan tetapi rasa persatuan dan kesatuan bangsa Indonesia saat ini dirasa semakin berkurang, mengalami krisis persatuan dan kesatuan. Banyak orang yang lebih mementingkan kepentingan pribadi daripada kepentingan umum, sehingga hilangnya persatuan dan kesatuan ini dapat menyebabkan timbulnya disintegrasi bangsa. hal ini terbukti dengan adanya perpecahan suku, perselisihan atau permusuhan dalam agama maupun antar agama. Gerakan pramuka merupakan organisasi pendidikan nonformal yang menyelenggarakan pendidikan kepanduan yang dilaksanakan di Indonesia. Kata "Pramuka" merupakan singkatan dari Praja Muda Karana, yang memiliki arti rakyat muda yang suka berkarya. Melalui gerakan pramuka tersebut bertujuan mendidik anak-anak dan pemuda Indonesia dengan prinsip-prinsip dasar dan Metode Kepramukaan yang pelaksanaannya disesuaikan dengan keadaan, kepentingan dan perkembangan untuk membangun kesatuan dan kesatuan.

\section{DAFTAR PUSTAKA}

https://www.google.com/url? sa=t\&rct=j\&q=\&esrc=s\&source=web\&cd=\&cad=rja\&uact= $\underline{\text { 8\&ved=2ahUKEwi12MTG1_PzAhWKbSsKHfHgAyMQFnoECAYQAQ\&url=http\%3A }}$ \%2F\%2Feprints.ums.ac.id\%2F23256\%2F13\%2FNASKAH_PUBLIKASI.pdf\&usg=AOv Vaw0co7WzMTNZ22L6YTikL-Si

https://www.google.com/url?sa=t\&rct=j\&q=\&esrc=s\&source=web\&cd=\&cad=rja\&uact= $\underline{8 \& v e d=2 \text { ahUKEwjB77We2_PzAhXKbSsKHSPABIQQFnoECAYQAQ\&url=http\%3A }}$ \%2F\%2Fjournal2.um.ac.id\%2Findex.php\%2Fjppk\%2Farticle \%2Fview\%2F6041\&usg=A OvVaw1Ru2D-LP9fOk_zGmfyqT04 
https://www.google.com/url?sa=t\&rct=j\&q=\&esrc=s\&source=web\&cd=\&cad=rja\&uact= 8\&ved=2ahUKEwjB77We2_PzAhXKbSsKHSPABIQQFnoECA4QAQ\&url=https\%3A $\% 2 \mathrm{~F} \% 2 \mathrm{Fgaruda} . r i s t e k b r i n . g o . i d \% 2 \mathrm{Fdocuments} \% 2 \mathrm{Fdetail} \% 2 \mathrm{~F} 855338 \& \mathrm{zusg}=\mathrm{AOvV}$ aw0v TVD8c3vb1Cu738itus1v 